\title{
Feasibility Evaluation on Single-Collector Collision Model to Separate Microplastics in Micro Bubble Flotation Process
}

\author{
Min-Ho Jang ${ }^{1 \oplus} \cdot{\text { Yong-Ho } \text { Choi }^{1 \odot} \cdot \text { Heung-Joe Jung }}^{2,+\odot} \cdot$ Yong-Hoon Jeong $^{3 \oplus} \cdot$ Dong-Heui Kwak $^{1 \oplus}$ \\ 'Department of Bio-convergence Science, Jeonbuk National University \\ ${ }^{2}$ Department of Biological Science, Sinkyung University \\ ${ }^{3}$ Center for Jeongeup Academy-Industry Cooperation, Jeonbuk National University
}

(Received November 18, 2020; Revised December 3, 2020; Accepted December 8, 2020)

Objectives: The single collector collision (SCC) model is a model that predicts the separation efficiency of particles based on the collision efficiency between microbubbles and particles in the particle separation process. In order to remove micro-plastics (MPs) particles, which have recently been known to be harmful, we tried to analyze the impact and separation efficiency of MPs based on the SCC model and evaluate its application feasibility.

Methods: Based on the SCC model, the collision efficiency prediction for MPs particle removal was simulated and the separation efficiency was evaluated. In addition, a series of flotation experiments were conducted using a flotation device that injects microbubbles to remove MPs particles suspended in water, and the experimental results and predicted values were compared.

Results and Discussion: Using the SCC model, the collision efficiency according to the size distribution of MPs particles was not significantly different from that of typical particles (clay, kaolin) in water. Based on this collision efficiency, the maximum removal efficiency of MPs particles separated from the water body is predicted to reach about $90 \%$. On the other hand, the initial collision-adhesion coefficient $\left(\alpha_{p b}\right)$ of the MPs particles based on the SCC model was 0.03 to 0.1 , showing a slight difference from the clay particles having the range of 0.3 to 0.4 . The flotation separation efficiency of the MPs particles evaluated and predicted by applying this initial collision-adhesion coefficient showed a range similar to the measured value. In addition, the particle separation efficiency according to the increase of the measured bubble volume concentration to improve the particle separation efficiency also showed a pattern similar to the predicted value.

Conclusions: In the flotation process, the initial collision-adhesion efficiency of the MPs particles predicted by the SCC model was lower than that of the kaolin particles. Based on the simple and simple model SCC theory, it was confirmed that it can be applied to the flotation separation analysis of MPs particles.

Keywords: Microbubble, Flotation, Microplastics, Particle, Single-collector Collision Model

The Korean text of this paper can be translated into multiple languages on the website of http:/jksee.or.kr through Google Translator. 


\title{
연구논문
}

\section{미세기포 부상분리 공정에서 미세플라스틱 분리를 위한 단일포집자 충돌 모델의 적용성 평가}

\author{
장민호 $^{1 \oplus} \cdot$ 최용호 $^{1 \oplus} \cdot$ 정흥조 $^{2+\oplus} \cdot$ 정용훈 $^{3 \oplus} \cdot$ 곽동희 $^{1 \oplus}$ \\ '전북대학교 바이오융합과학과 \\ 2신경대학교 생명과학과 \\ 3전북대학교 정읍산학연협력지원센터
}

목적 : 단일포집자 충돌(SCC) 모델은 입자분리공정에서 미세기포와 입자 간의 충돌효율에 기초하여 입자의 분리효 율을 예측하는 모델이다. 최근 위해가 알려진 미세플라스틱(MPs) 입자제거를 위하여, SCC 모델을 토대로 미세플 라스틱의 충돌 및 분리효율을 해석해 보고 그 적용 타당성을 평가하고자 하였다.

방법: SCC 모델을 토대로 MPs 입자의 충돌효율 예측을 모의하고, 분리효율을 평가하였다. 아울러, 수중에 부유된 MPs 입자를 제거하기 위해 미세기포를 분사하는 부상분리 장치를 이용하여 일련의 부상분리 실험을 실시하고 그 실험결과와 예측값을 비교하였다.

결과 및 토의: SCC 모델을 이용하여 MPs 크기분포에 따른 충돌효율은 수중의 통상적 입자(점토, 카올린)와 크게 다르지 않았다. 이 충돌효율을 기초로 수체로부터 분리되는 MPs 입자의 최대 제거 효율은 약 $90 \%$ 에 달할 것으로 예측되었다. 반면, SCC 모델로 확인된 MPs 입자의 초기 충돌-부착 계수 $\left(\alpha_{p b}\right)$ 는 $0.03 \sim 0.1$ 로서 $0.3 \sim 0.4$ 범위를 보 이는 점토 입자와 다소 큰 차이를 보였다. 이 초기 충돌-부착계수를 적용하여 평가 예측한 MPs의 부상분리 효율은 실측값과 유사한 범위를 나타내었다. 또한 입자분리 효율 향상을 위하여 실측한 기포체적농도의 증가에 따른 입자 분리효율도 예측값과 유사한 패턴을 보였다.

결론 : 부상분리 공정에서 SCC 모델로 예측한 MPs 입자의 초기 충돌-부착효율은 kaolin 입자에 비하여 낮은 값을 나타내었으며, 미세기포 부상실험 장치를 이용하여 얻은 실측값과 SCC 모델에 의한 모의값을 비교한 결과, 단순하 고 간편한 모델인 SCC 이론을 바탕으로 MPs 입자의 부상분리 해석에 적용이 가능함을 확인하였다.

주제어 : 미세기포, 부상, 미세플라스틱, 입자, 단일포집자 충돌 모델

\section{1. 서론}

최근 전세계적으로 플라스틱의 생산량은 약 3 억톤 이상이 생산되며, 연간 약 $4 \%$ 정도 증가하고 있으며, 그 중에서 거의 $94 \%$ 가 매립지에 버려지거나 환경으로 방출된다. ${ }^{1,2)}$ 이렇게 방출된 플라스틱은 호수나 강, 바다 등 수생태계에서 발견되 고 있다.,3) 또한 플라스틱은 인간의 생활과도 밀접한 연관이 있으며, 악영향을 미칠 수 있다.-7) 수중에 존재하는 플라스틱 은 광분해와 생분해 그리고 물리적인 파쇄와 같은 물리, 화학, 생물학적 과정에 의해서 $5 \mathrm{~mm}$ 미만의 플라스틱 파편이 생성 되는데 이것을 미세플라스틱(Microplastics, MPs)으로 정의한 다.8) 이러한 MPs는 시간이 지나도 분해되지 않고 환경에 존재 하며, 큰 비표면적과 강한 소수성으를 가지기 때문에 중금속과
같은 독성유기화학물질 등을 흡착할 수 있고 ${ }^{10-12)}$, 수체에서 분리가 어렵다. 이처럼 수체에서 MPs의 다양한 분포와 생태 계에서의 영향에 대한 조사가 진행되어 왔다.

MPs를 제거하기 위하여 응집침전 및 부상분리 그리고 여과 와 같이 다양한 기술을 이용한 제거연구가 진행되고 있다.,13) 자연수계에 존재하는 여러 물질들은 일반적으로 침전 기작이 일어날 수 있다. 반면, MPs의 경우에는 침전되지 않고 수체에 부유하면서 추가적인 환경오염을 일으키고 있다. 응집을 통한 침전 연구가 진행되고 있지만 자연수체에서 침전되면 제거되 는 것이 아니라 퇴적층 표면에 지속적으로 축적되어 환경에 영향을 미칠 수 있다. 이와는 다르게 부상분리는 기포를 이용 하여 부상시킴으로써 잔류하는 MPs를 제거할 수 있어 추가적 인 환경오염을 방지할 수 있다. 
부상분리란 접촉영역에서 일련의 응집과정을 거친 후 가압 된 공기를 분사하여 압력차이로 인해 생성되는 미세기포와 결합된 floc을 분리영역에서 제거하는 방법이다. ${ }^{14)}$ 최근 미세 기포와 입자간의 화학적인 결합에 대한 이론적인 접근으로 다양한 오염물제거에 대한 연구는 많이 진행되었다. ${ }^{15,16)}$ 반면 에, 수중에 존재하는 MPs의 일반적인 제거에 대한 연구는 그 리 많지 않으며, 부상분리를 이용하여 MPs를 제거하는 연구 는 거의 없다. 최근에 연구된 미세기포를 이용하여 MPs를 제 거하는 문헌에서는 양전하의 버블을 이용하여 $\mathrm{MPs}$ 에 부착하 기 쉬운 조건으로 부상분리를 진행하였고, 입자 크기별 제거 율과 MPs 종류별 제거율을 제시하였다. 문헌에서의 제거율은 최대 $48.7 \%$ 정도로 높지는 않지만 제거 가능성을 확인할 수 있었다. ${ }^{13)}$

부상분리 효율에 대한 해석은 기포와 입자의 접촉효율을 계산함으로써 기포-입자 간의 결합이 이루어지는 단일포집자 충돌(Single-collector collison, $\mathrm{SCC}$ )이론으로 간편하게 사용 할 수 있고, 비교적 쉽게 해석할 수 있기 때문에 신속한 처리가 가능하다. 또한, 충돌률을 이용한 입자와 기포간의 충돌효율 Single Collector Collision Efficiency (SCCE, $\eta_{T}$ ) 로 표현함으 로써 부상분리에 대한 기본적인 원리를 설명할 수 있다. ${ }^{17)}$ SCCE, $\eta_{T}{ }^{18)}$ 는 다음과 같은 요소들의 식 (1)로 표현할 수 있다.

$$
\eta_{T}=\eta_{D}+\eta_{I}+\eta_{G}+\eta_{I N}
$$

여기서, $\eta_{D}$ 는 브라운 확산(Brownian diffusion)을 나타내고, $\eta_{I}$ 는 입자의 포착(interception), $\eta_{I N}$ 는 관성(inertia)을 나타낸 다. 마지막으로 $\eta_{G}$ 는 중력에 의한 침강(gravity force)이며 각 인자들을 이용한 식으로 기포와 수중의 floc의 결합에 대한 동역학을 1차방정식으로 식 (2)와 같이 표현된다.

$$
d N_{P} / d t=-\left(\alpha_{p b} \eta_{T}\right) A_{b} U_{p b} N_{b} N_{p}
$$

여기서, $\alpha_{p b}$ : 입자와 기포의 충돌계수

$$
\begin{aligned}
A_{b} & : \text { 기포의 분사 표면적, } \mathrm{L}^{2} \\
U_{p b} & : \text { 기포-입자 응집체의 상승속도, } \mathrm{LT}^{-1} \\
N_{b} & : \text { 기포의 수 } \\
N_{p} & : \text { 입자의 수 }
\end{aligned}
$$

마지막으로, 접촉영역에서 기포를 이용한 입자분리효율(X) 을 예측하기 위해 다음의 식을 모델에 적용하여 비교하였다.

$$
X=\frac{N_{p, i}-N_{p, e}}{N_{p, i}}=1-\exp \left(-\frac{1}{12} \frac{\alpha_{p b} \eta_{T} d_{b} \phi_{b} g}{\mu} \tau\right)
$$

여기서, $\Phi_{b}$ : 기포 체적농도, $\mathrm{L}^{3} / \mathrm{L}^{3}$

$$
\begin{aligned}
& g: \text { 중력가속도, } \mathrm{M} / \mathrm{T}^{-2} \\
& \tau: \text { 부상조의 체류시간, } \mathrm{T} \\
& \mu: \text { 물의 점성계수, } \mathrm{ML}^{-1} \mathrm{~T}^{-1}
\end{aligned}
$$

위의 SCC 이론을 적용하여 이산화탄소 기포를 이용한 무 기 입자의 분리 및 부상효율을 실제 실험과 비교하고 이를 통해 용존이산화탄소부상(dissolved carbon dioxide flotation, $\mathrm{DCF}$ )에 대한 모델 적용성을 확인한 연구도 진행된 바 있다. ${ }^{19)}$

본 연구에서는 최근 플라스틱 사용량의 증가로 인해 수체에 축적되고 있는 MPs 농도가 상승되고 있는 현실적 문제를 해 소하기 위하여, MPs 입자에 대한 부상분리 공정에서의 기포 와 입자의 충돌효율을 $\mathrm{SCC}$ 모델을 통하여 해석하고, 이 결과 를 토대로 크기별 MPs 입자에 대한 일련의 부상분리 실험을 실시하였다. 또한, 실제 실험에 의한 관측값과 $\mathrm{SCC}$ 이론을 통하여 얻어진 예측값을 상호 비교함으로써 MPs 입자의 초 기 충돌-부착 계수에 대한 평가를 실시하고, 궁극적인 MPs 입자의 부상 제거율에 대한 모델의 적용성을 확인하고자 하 였다.

\section{2. 재료 및 방법}

\section{1. 실험재료}

본 실험에서는 다음의 Fig. 1 에 나타낸 바와 같이 크기에 따라 분류된 MPs 입자를 증류수에 혼합한 인공시료를 제조 하여 사용하였으며, 실험에 사용된 MPs의 재질은 자연수계 에 가장 많이 배출되며 쉽게 부유되는 특성 때문에 다른 종류 의 MPs보다 더 큰 잠재적인 위험성을 나타내는 PE (poly ethylene, Cospheric LLC, USA)를 사용하였다. ${ }^{7)}$ 실험에서 사 용된 MPs 입자의 성상을 다음의 Table1에 제시하였다. 부상 처리를 하기 위해서 투입되는 응집제는 통상적으로 많이 사용 되는 PAC (ploy aluminum chloride)를 $120 \mathrm{mg} / \mathrm{L}$ 로 제조하여 사용하였으며, 응집에 요구되는 알칼리도의 보충을 위하여 알칼리제로는 소석회 $\left(\mathrm{Ca}(\mathrm{OH})_{2}\right)$ 를 사용하였다.

Table 1. Density and particle size of MPs used in the experiment.

\begin{tabular}{ccr} 
Materials & $\begin{array}{c}\text { Particle size } \\
(\text { um })\end{array}$ & $\begin{array}{r}\text { Density } \\
\left(\mathrm{kg} / \mathrm{m}^{3}\right)\end{array}$ \\
& $27 \sim 32$ & \\
PE & $53 \sim 63$ & 995 \\
& $125 \sim 150$ & \\
\hline
\end{tabular}

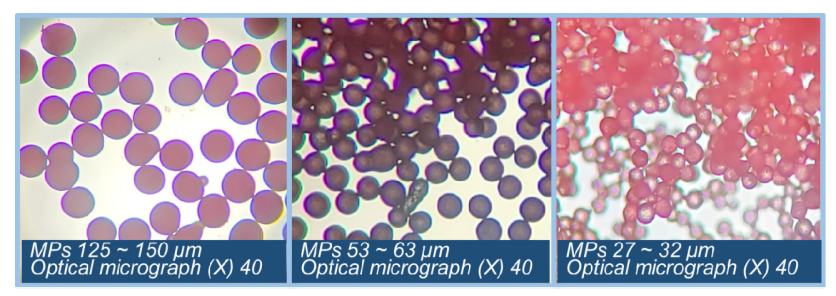

Fig. 1. Photographs of three size groups of MPs particles used in this study. 
Table 2. Simulation parameters for SCC model in contact zone.

\begin{tabular}{|c|c|c|}
\hline \multirow{9}{*}{$\begin{array}{l}\text { Single } \\
\text { collector } \\
\text { collision } \\
\text { efficiency }\end{array}$} & Parameters & Value \\
\hline & $k_{B}$ & $1.38 \times 10^{-23} \mathrm{~J} / \mathrm{K}$ \\
\hline & $T$ & $293 \mathrm{~K}\left(20^{\circ} \mathrm{C}\right)$ \\
\hline & $g$ & $9.81 \mathrm{~m} / \mathrm{s}^{2}$ \\
\hline & $\rho_{p}$ & 995 kg/m³ \\
\hline & $\rho_{w}$ & $998.23 \mathrm{~kg} / \mathrm{m}^{3}$ \\
\hline & $d_{b}$ & $30,60,95 \mu \mathrm{m}$ \\
\hline & $d_{p}$ & $30,55,135 \mu \mathrm{m}$ \\
\hline & $v$ & $1.007 \times 10^{-6} \mathrm{~m}^{2} / \mathrm{sec}$ \\
\hline \multirow{6}{*}{$\begin{array}{l}\text { Particle } \\
\text { removal } \\
\text { efficiency }\end{array}$} & $a_{p b}$ & $0.3,0.4$ \\
\hline & $\eta_{T}$ & $0.5 \sim 0.9$ \\
\hline & $d_{b}(\mu \mathrm{m})$ & $20 \sim 80^{23)}$ \\
\hline & $\Phi_{b}\left(\mathrm{~L} / \mathrm{m}^{3}\right)$ & $2.4 \sim 4.8^{24)}$ \\
\hline & $\tau$ & $600 \mathrm{sec}$ \\
\hline & $\mu \mathrm{m}$ & $0.001 \mathrm{~kg} / \mathrm{m} \cdot \mathrm{s}$ \\
\hline
\end{tabular}

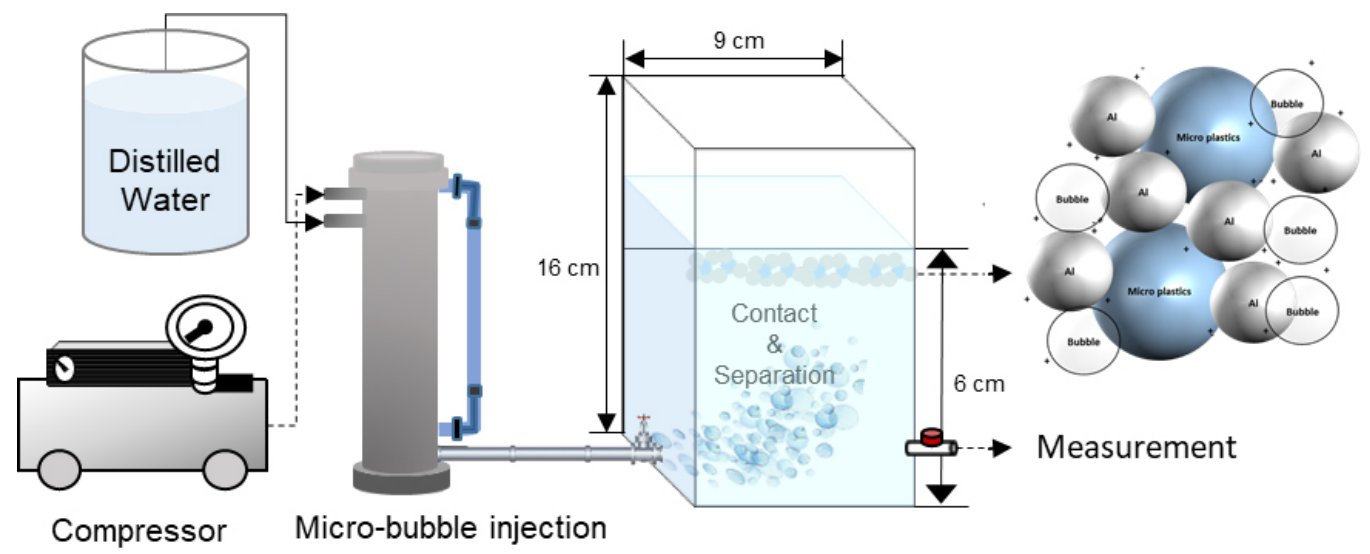

Fig. 2. Schematic diagram of micro-bubble flotation device to separate MPs and kaolin particles.

\section{2. 실험방법 및 분석}

본 연구에서는 MPs 입자를 제거하기 위해 실험실 규모의 회분식 미세기포 부상분리 실험장치를 제작하였다. 가압장치 (saturator) 부피는 약 $0.67 \mathrm{~L}$ 이며, 압력을 견뎌낼 수 있도록 스테인리스로 제작하였다. 반응칼럼의 크기는 직경 $9 \mathrm{~cm}$, 높 이 $16 \mathrm{~cm}$ 의 사각형의 아크릴 컬럼에 사전에 제조된 인공시료 를 적정량 주입하여 실험을 실시하였다. Jar test를 통해 얻어진 적정 응집제 주입량을 컬럼에 주입하고 급속 $(150 \mathrm{rpm})$ 으로 1 분 완속(30 $50 \mathrm{rpm})$ 으로 10 분 동안 교반하여 응집을 유도하 고, MPs 입자와 미세 기포가 원활히 충돌-결합할 수 있도록 가압수(milky water)를 컬럼의 하부를 통하여 주입하였다. Air bomb을 이용하여 가압장치의 압력 $3.0 \sim 6.0 \mathrm{~atm}$ 에서 형성된 가압수를 주입한 뒤 10 분의 부상 분리시간을 설정하여 MPs 입자의 부상분리 효율을 측정하였다.

부상이 끝난 후에 컬럼 하단에서 시료를 채취를 하여 분석하
였다. ${ }^{20)}$ 각 압력조건 변화에 대한 입자의 제거율(R, \%) 계산은 부상 전과 후의 탁도(2100P, HACH, USA)를 매회 5 회 이상 측정하여 대표값을 결정하고, 별도로 산정된 SS 관계식에 따 라서 SS로 환산하여 제거효율을 계산하였다. 또한, DAF 공정 에서 MPs 입자와 기포의 충돌과 부착 효율을 SCC 모델을 통하여 해석하였으며, 프로그램은 널리 사용되는 $\mathrm{S} / \mathrm{W}$ 인 MATLAB (R2018a, Mathwork, USA)을 활용하였다. SCC 이 론과 모델에 적용된 인자들은 Table 2에 제시하였으며 ${ }^{21,22)}$, 미세기포 부상분리 실험장치의 대략적인 모식도를 Fig. 2에 나타내었다.

$$
\begin{aligned}
& R(\%)=\frac{C_{0}-C_{1}}{C_{0}} \times 100 \\
& \text { 여기서, } C_{0}=\text { 부상 전 원수의 } \mathrm{SS}(\mathrm{mg} / \mathrm{L}) \\
& C_{1}=\text { 부상 후 처리수의 } \mathrm{SS}(\mathrm{mg} / \mathrm{L})
\end{aligned}
$$




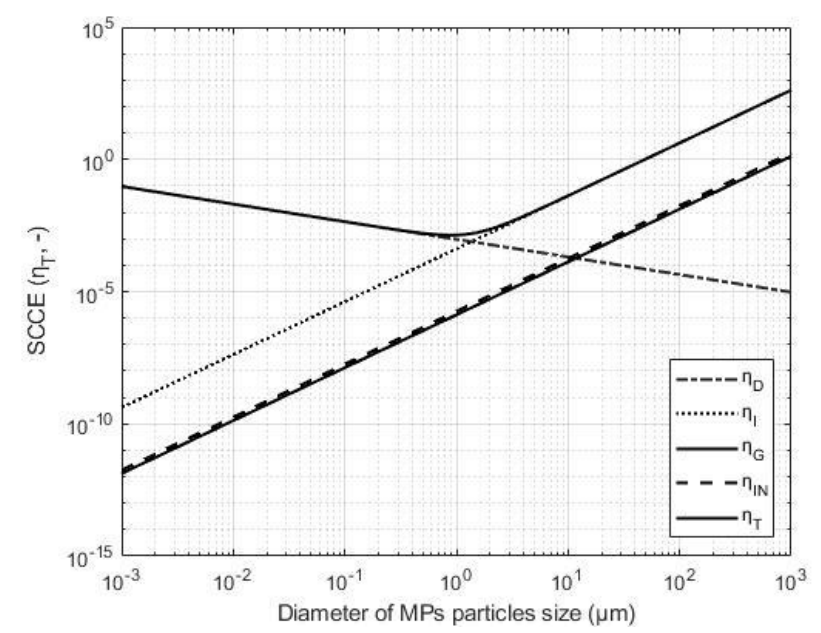

Fig. 3. Single-collector collision efficiency (SCCE) depending on floc size.

\section{3. 결과 및 고찰}

\section{1. 입자와 기포의 충돌효율}

기포와 입자의 충돌효율은 서로 일정거리의 범위에 존재할 때, 기포와 입자표면의 전기화학적인 특성에 의해 결정된다. ${ }^{18)}$ Floc의 크기가 작을수록 부상에 더 유리하게 작용할 수 있으 며 ${ }^{23)}$, 입자의 크기와 기포의 크기는 비례관계에 있어 비슷한 크기의 입자와 기포에서 최적의 충돌효율을 가진다. ${ }^{24)}$ 따라서 본 연구에서는 MPs 입자 크기에 따라서 나타나는 기포와 입자 의 충돌효율을 살펴보기 위하여 SCC 모델을 통한 해석을 실 시하였다. 부상분리 접촉존에서의 모델링은 문헌에 제시된 기포(평균직경 $60 \mu \mathrm{m})^{25-27)}$, floc (비중 $\left.1,003 \mathrm{~kg} / \mathrm{m}^{3}\right)^{28)}$, 수온(평 균 $\left.20^{\circ} \mathrm{C}\right)$ 의 조건을 기준으로 기포와 MPs 입자의 충돌효율을 모의하였다. 충돌 효율은 식 (1)에 제시된 $\mathrm{SCC}$ 이론에 따라 모의하고 그 결과를 Fig.3에 제시하였다.

기포를 $60 \mu \mathrm{m}$ 로 가정하여 기포와 입자의 충돌효율을 모의 하였을 때, 총 충돌효율 $\left(\eta_{T}\right)$ 의 변화에 영향을 미치는 주요 인자는 브라운 확산 $\left(\eta_{D}\right)$ 과 입자의 포착 $\left(\eta_{I}\right)$ 이었다. 두 인자는 floc의 직경에 따라 각각 부상효율에 미치는 영향이 달랐는데, $1 \mu \mathrm{m}$ 이하에서는 $\eta_{D}$ 가, 그리고 $1 \mu \mathrm{m}$ 이상에서는 $\eta_{I}$ 이 주로 효율에 영향을 미치는 것으로 나타났다. 반면에, 중력에 의한 침강 $\left(\eta_{G}\right)$ 과 관성 $\left(\eta_{I N}\right)$ 은 floc의 직경이 부상효율에 크게 영향 을 미치지 못하는 결과를 보였다. 이 모의 결과는 kaolin 입자 의 충돌효율 곡선과 유사한 형태를 나타내었다. 이는 기존의 kaolin 입자와 MPs 입자의 비중을 비롯한 이화학적 특성이 서로 크게 다르지 않기 때문에 모의결과 또한 유사한 패턴을 보인 것으로 여겨진다.

미세기포 부상분리 실험에 분사되는 기포의 크기는 가압장 치의 압력이 높아질수록 평균 기포 크기가 작아지는 것으로 알려져 있다. ${ }^{25,26)}$ 다음 Fig. 4은 압력이 높아질수록 작아지는

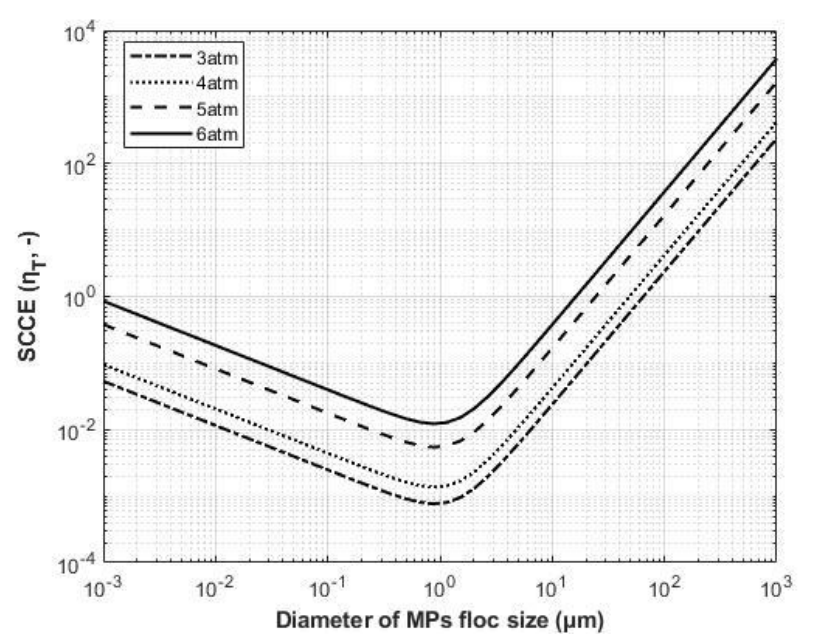

Fig. 4. Variation of SCCE in terms of MPs size for four operation pressures of saturator.

기포 크기에 따라서 MPs의 충돌효율을 입자의 크기에 따라서 표현하였다. 평균 기포 입경의 크기가 작아질수록 충돌효율이 증가하였으며, 응집제와 MPs가 형성하는 floc의 크기가 $1 \mu \mathrm{m}$ 을 기준으로 하여 작거나, 커질수록 충돌효율이 증가하는 것 을 알 수 있었다. 이러한 결과를 토대로 작은 기포를 이용(가압 장치의 압력을 높게 운전)하여 부상분리를 수행하였을 때, 기 포와 MPs 입자간 충돌효율을 상승시켜 MPs 입자의 부상제거 효율을 향상시킬 수 있음을 확인하였다.

\section{2. 실험 관측값과 모델 예측값의 부상효율 비교}

접촉시간에 따른 MPs 입자의 부상효율(X)은 식 (3)에서처 럼 기포와 입자의 충돌효율 $\left(\eta_{T}\right)$ 을 기초로 경험적으로 얻어지 는 입자의 초기 충돌-부착 계수(initial collision-attachment coefficient, $\alpha_{p b}$ ), 주입된 기포의 체적농도 $\left(\Phi_{b}\right)$, 기포와 MPs가 충돌-부착하여 부상분리되는데 필요한 체류시간 $(\tau)$ 등의 여러 가지 주요 운전인자와 점성계수 $(\mu)$ 와 같은 처리 조건들이 복 합적으로 결합되어 결정된다. 본 연구에서는 입자크기와 압력 그리고 접촉시간에 따라 달라지는 SCC 모델의 충돌효율을 기초로 얻어진 이론적 부상분리 효율의 예측값과 실제 실험에 서 관측된 부상효율을 상호 비교하였다.

다음의 Fig.5는 MPs 입자의 크기별로 가압장치의 압력을 달리 운전하였을 경우 접촉시간에 따라 변화하는 제거율을 나타낸 것이다. 가압장치의 운전 압력이 상승할수록 입자의 분리효율이 좋은 것으로 알려져 있으며 ${ }^{24)}$, 본 실험에서는 가압 장치의 운전압력 중 $4 \mathrm{~atm}$ 에서 MPs 입자의 제거효율이 가장 좋은 결과를 나타내었다. 운전압력 5 6 atm에서 $4 \mathrm{~atm}$ 보다 실제 실험의 분리효율이 감소한 이유는 높은 압력에서 가압수 (milky water)의 분사 주입과정에서 발생되는 거대 기포 (macro-bubbles)의 수리적 전단력에 의해 부착효율의 감소와 기포-입자 결합체(bubble-particle agglomerates)의 기포 탈착 


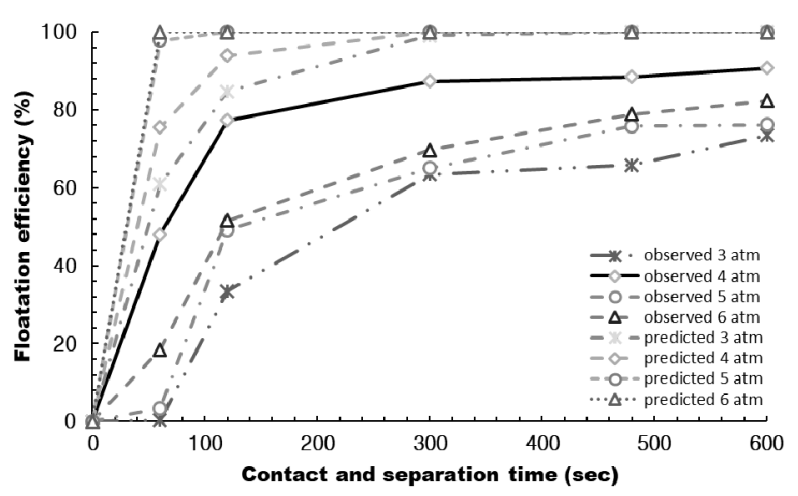

(a) Diameter of MPs particles, $27 \sim 32 \mu \mathrm{m}$

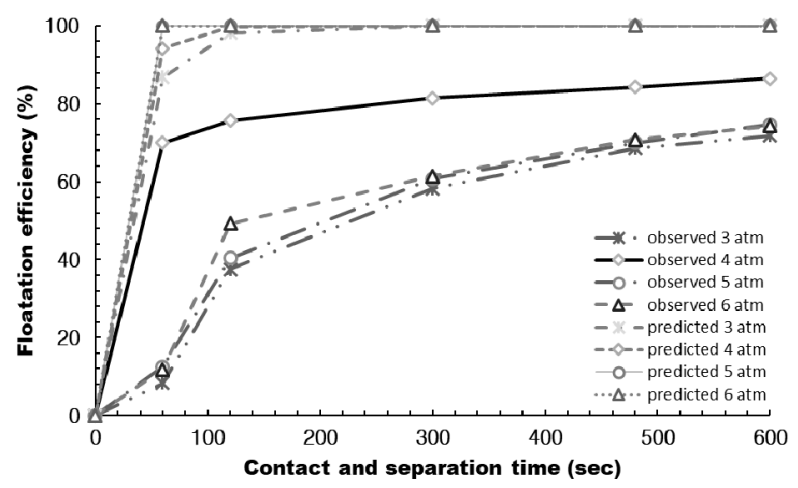

(b) Diameter of MPs particles, $53 \sim 63 \mu \mathrm{m}$

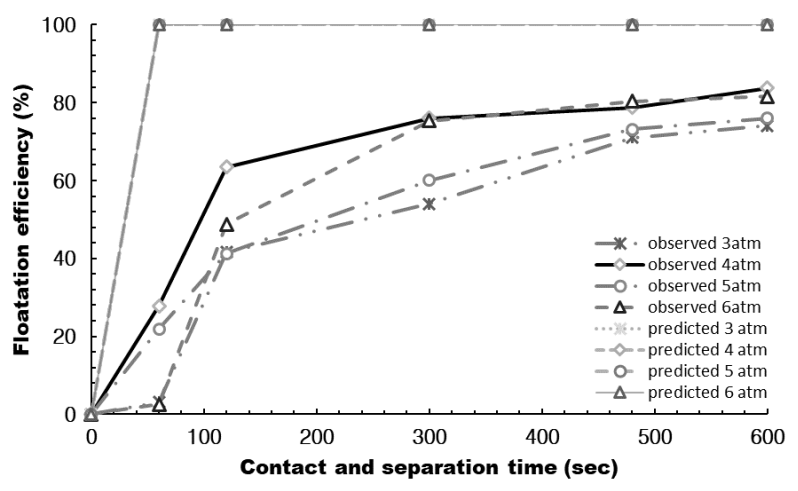

(c) Diameter of MPs particles, $125 \sim 150 \mu \mathrm{m}$

Fig. 5. Variation of particle removal efficiency in terms of flotation time for four operation pressures of saturator.

이 나타나는 현상을 현장 실험에서 관찰되었다. 이러한 문제 는 회분식 실험실규모 실험장치에서 갖는 한계에서 유발된 것이며 보다 견고한 부상분리 장치에서는 이와 같은 거대 기 포발생은 제어할 수 있다. ${ }^{29)}$

일반적인 응집침전과는 다르게 MPs 입자의 부상분리에서 는 완속교반시간을 $600 \mathrm{sec}$ 로 짧게 설정하였는데, 이는 floc의 크기가 크지 않아도 기포와 부착될 수 있는 일정 크기만 만족 하면 부상분리가 가능하기 때문에 긴 floc 형성시간을 필요로 하지 않는다. ${ }^{30,31)}$ 시간에 따른 실험결과에서는 입자 크기에 상관없이 분리시간 $120 \mathrm{sec}$ 이후부터 제거효율이 점차 안정된 경향을 보이는 반면, $\mathrm{SCC}$ 모델을 기초로 한 예측 결과에서는 기포 접촉 후 약 $60 \mathrm{sec}$ 에서부터 빠르게 분리되어 안정화되는

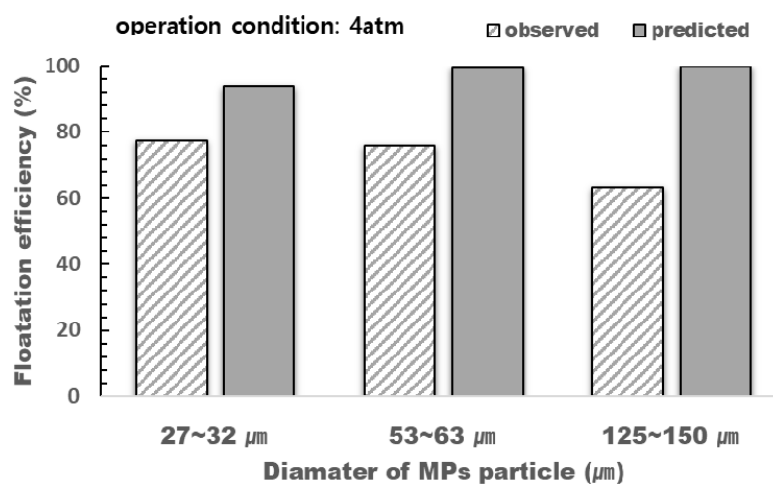

(a) Contact and separation time, $120 \mathrm{sec}$

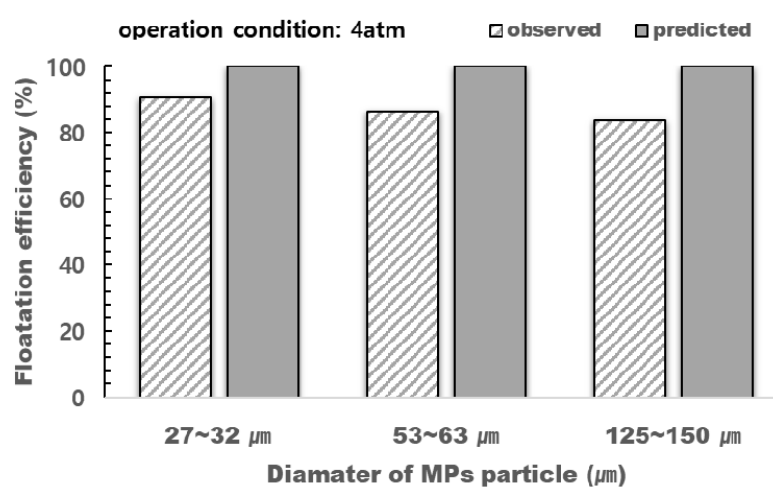

(b) Contact and separation time, $600 \mathrm{sec}$

Fig. 6. Comparison of particle removal efficiency for three diameter ranges of MPs particle in bubble flotation experiments.

제거효율을 나타내었다. 이와 같은 실험 관측값과 모델 예측 값과의 차이는 일반적으로 실제 기포의 크기분포는 수 $\mu \mathrm{m}$ 에 서 수십 $\mu \mathrm{m}$ 까지 넓게 발생함에 따라 작은 기포와 결합한 입자 는 느리게 상승하여 부상분리 시간이 길게 소요되는 반면, $\mathrm{SCC}$ 모델은 기포의 대표치(평균치)로 적용되어 입자 분리효 율 예측값도 평균적 대표치로 나타나는 원인으로 여겨진다.

다음 Fig. 6은 MPs 입자의 크기별로 부상분리되는 효율의 차이를 나타내고 있으며, 분리시간을 초기 부상분리 효율과 최종 부상분리 효율의 차이를 알아보기 위하여 MPs 크기별로 비교하였다. Fig.6(a)에서 제시된 것처럼 부상분리 시간 600 $\sec$ 에서는 입자의 제거 효율이 크기별로 큰 차이를 보이지 않았지만, Fig. 6(b)에서는 $120 \mathrm{sec}$ 의 부상분리 시간에서는 크기별로 다소 차이를 보이고 있다. 특히, $125 \sim 150 \mu \mathrm{m}$ 의 큰 입자군에서 부상분리 초기에 제거효율이 낮게 나타나고 있다. 반면, MPs 입자의 크기별로 SCC 모델을 통하여 예측한 부상분리 효율은 입자가 클수록 효율이 높아질 것으로 예측되 어 실험값과 대조되는 모습을 보이고 있다. 이는 수중에 존재 하는 일반적인 입자의 크기가 클 경우 기포와 접촉-부착할 수 있는 표면적이 넓어 많은 수의 기포가 부착하여 큰 입자의 분리효율이 높아진다는 이론적 배경 ${ }^{22)}$ 을 갖는 것이나, MPs 입자의 부상실험에서는 실제 실험값과 차이를 나타내고 있다. 
이 상반된 결과는 MPs 입자의 표면이 미세기포와의 충돌-부 착에 kaolin과 같은 수중 입자에 비하여 불리한 특성을 갖고 있을 것이라는 점을 유추할 수 있다. 이에 따라 다음 절에서는 MPs 입자의 초기 충돌-부착 효율을 살펴보았다.

\subsection{MPs 입자의 초기 충돌-부착 계수 평가}

초기 충돌-부착 계수(initial collision-attachment coefficient, $\alpha_{p b}$ )는 부상분리공정에서 주로 입자표면의 이화학적 특성에 따라 결정되는 계수로서, 입자가 미세 기포에 충돌하여 부착 되는 성질을 말한다. 이러한 입자와 기포의 부착효율은 정전 기적 특성과 floc의 크기 등의 영향을 받는다. ${ }^{33)}$ 본 연구에서는 기존의 다른 무기입자(clay, kaolin)의 $\alpha_{p b} 0.3 \sim 0.4$ 를 적용한 ${ }^{34)}$ $\mathrm{SCC}$ 모델에 대한 모의값과 실측값이 다소의 차이를 보였다. 일반적으로 무기입자는 $\mathrm{pH}$ 6 7일 때, Zeta 전위가 약 +10 $\mathrm{mV} \sim-30 \mathrm{mV}$ 를 나타내는 것으로 35,36 알려져 있는 반면 MPs 입자의 경우 전형적인 무기입자와 다른 표면특성을 가져 Zeta 전위는 약 $-100 \mathrm{mV}$ 를 나타낸다. ${ }^{37}$ 이러한 기본적인 입자표면 의 이화학적 특성의 차이로 인해 기존의 kaolin과 같은 무기입 자의 $\alpha_{p b}$ 보다 더 낮을 것으로 예상됨에 따라, $\mathrm{SCC}$ 모델에 의한 예측결과와 실제 실험값을 토대로 MPs 입자의 부상분리 해석에 적용가능한 $\alpha_{p b}$ 값을 평가하였다.

Fig.7(a)는 부상분리 효율이 가장 높았던 $4 \mathrm{~atm}$ 에서 MPs 입자의 크기에 따른 실험 결과에 대하여 초기 충돌-부착 계수 $\alpha_{p b}$ 값을 다양하게 변화시켜 모의한 결과와 비교하였다. MPs $27 \sim 32 \mu \mathrm{m}$ 에서 실험값과 모의값이 일치하는 $\alpha_{p b}$ 의 범위는 $0.03 \sim 0.1$ 로서, 기존에 알려진 kaolin 무기입자의 $\alpha_{p b}$ 값에 비 하여 크게 낮은 값을 보였다. 이러한 결과는 MPs 입자의 표면 특성이 수중에 존재하는 일반적인 무기입자에 비하여 기포와 의 부착 친화력(bubble attachment affinity)이 적다는 사실을 암시한다.

Fig.7(a)에 비하여 Fig.7(b)-(c)에 나타낸 큰 MPs 입자군의 제거효율을 볼 때, $\mathrm{MPs}$ 의 크기가 증가할수록 $\alpha_{p b}$ 값이 0.01 $\sim 0.1$ (MPs 입경, 53 63 $\mu \mathrm{m}$ )와 0.003 0.01 (MPs 125 150 $\mu \mathrm{m})$ 로 더욱 낮아졌다. 이와 같은 결과는 입경이 큰 MPs 입자 가 미세기포와 부착을 위한 넓은 표면적을 제공하더라도 MPs 입자의 표면특성이 기본적으로 무기성 입자에 비하여 기포와 의 친화력이 크지 않은 데서 기인된 것으로 볼 수 있다. 또한, 부상분리를 통한 MPs 입자의 효율적 제거를 위해서는 입자 표면특성의 개질이 중요하다는 점을 내포한다.

\section{4. 기포체적농도에 따른 MPs 입자의 부상분리 효율}

앞에서 살펴본 바와 같이, MPs 입자의 표면이 미세기포와의 충돌 부착에 유리하지 않은 특성을 고려하여, MPs 입자의 낮 은 초기 충돌-부착 계수를 보완하기 위하여 기포체적농도를 증가시켜 입자의 제거효율 상승을 도모할 수 있는지의 여부를

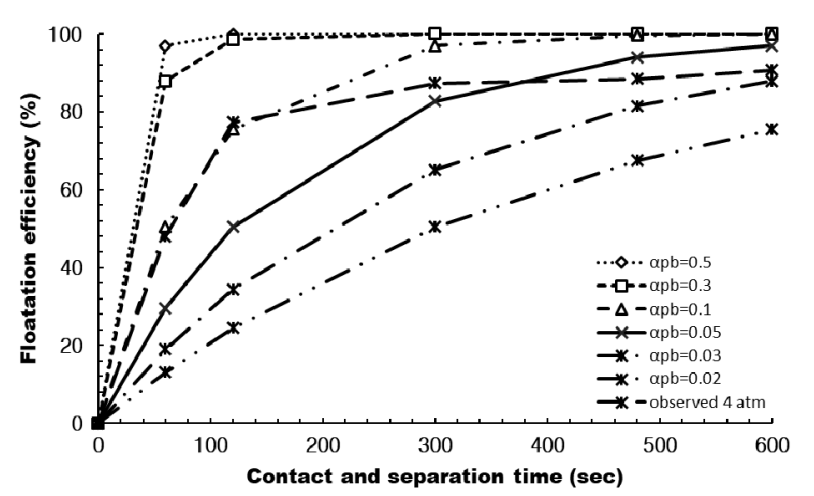

(a) MPs $27 \sim 32 \mu \mathrm{m}$

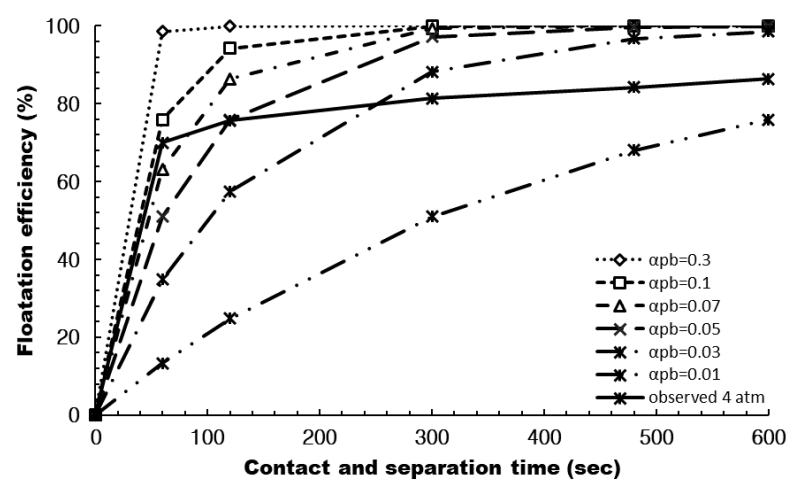

(b) MPs $53 \sim 63 \mu \mathrm{m}$

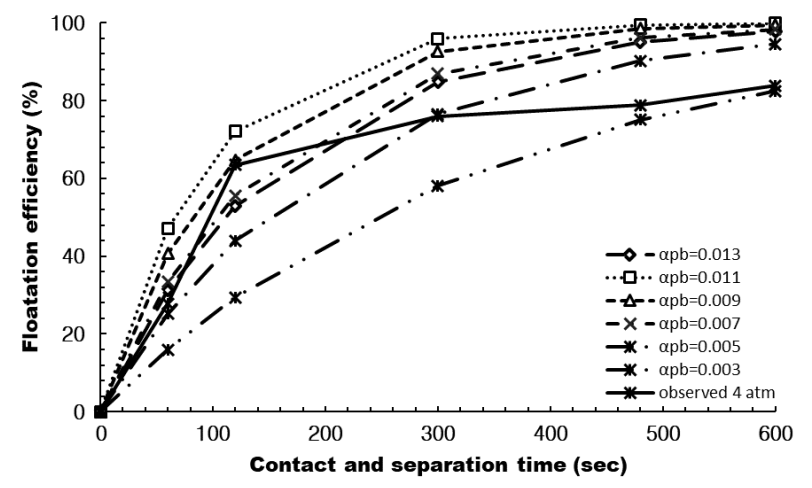

(c) MPs $125 \sim 150$ um

Fig. 7. Comparison of experimental values according to MPs size and simulation values of initial attachment efficiency.

실험을 통하여 살펴보았다. 통상 부상분리 공정에서는 기포체 적농도의 증가 운전에 따라 미세기포의 주입량이 증가하면 응집된 floc과 주입된 기포의 충돌·부착효율이 증가하여 그에 따라 부상분리 효율이 상승하게 된다. ${ }^{38)}$ 미세기포를 이용한 부상분리에서 기포의 체적농도(Bubble volume concentration: $\mathrm{BVC}$ )는 전체 기포발생량으로 표현할 수 있으며, 기포의 개수 농도(Bubble number concentration; BNC)로 표현하기도 한다. 이론적 기포 체적농도는 실제 특정조건에서 압력차이에서부 터 비롯되어 발생된 기체의 체적을 계산한 것이며, 실제 발생 되는 기체의 양을 측정한 값은 아니다. $\mathrm{BVC}$ 는 기존에 문헌에 서 시료 부피에 따른 가압수(saturated water, milky water)의 양과 가압장치의 압력값을 토대로 계산한 값인 $2.4 \sim 4.8 \mathrm{~L} / \mathrm{m}^{3}$ 


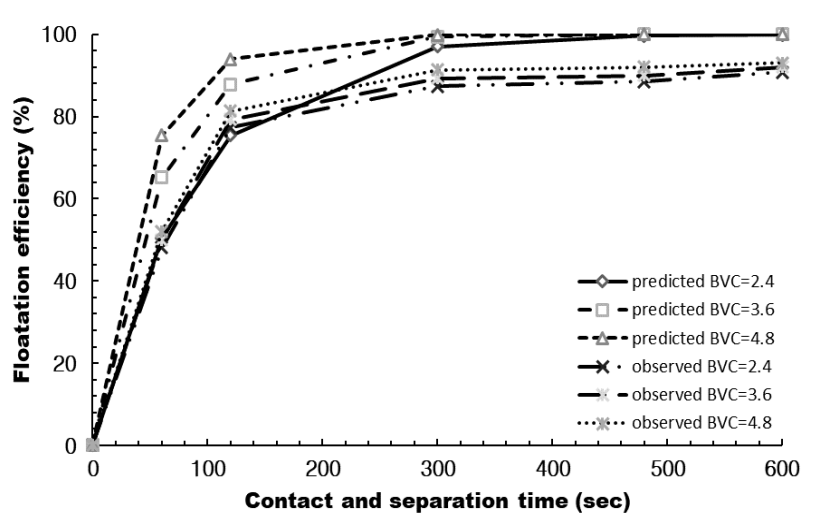

(a) MPs $27 \sim 32 \mu \mathrm{m}$

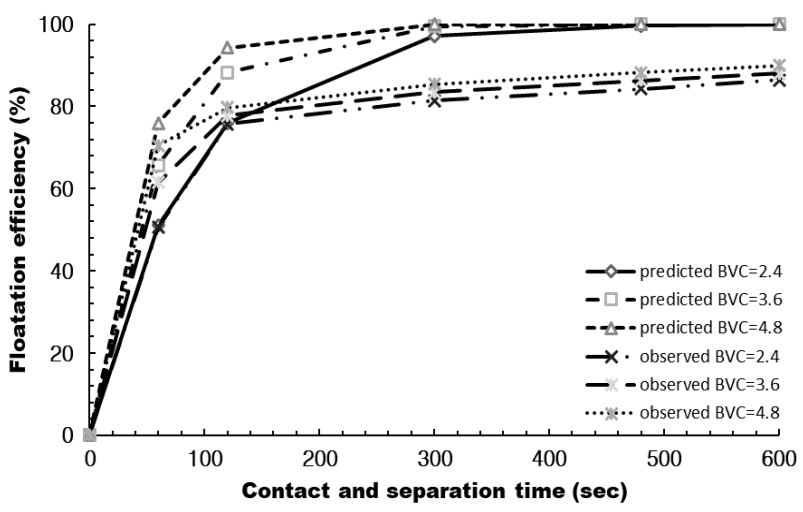

(b) MPs $53 \sim 63 \mu \mathrm{m}$

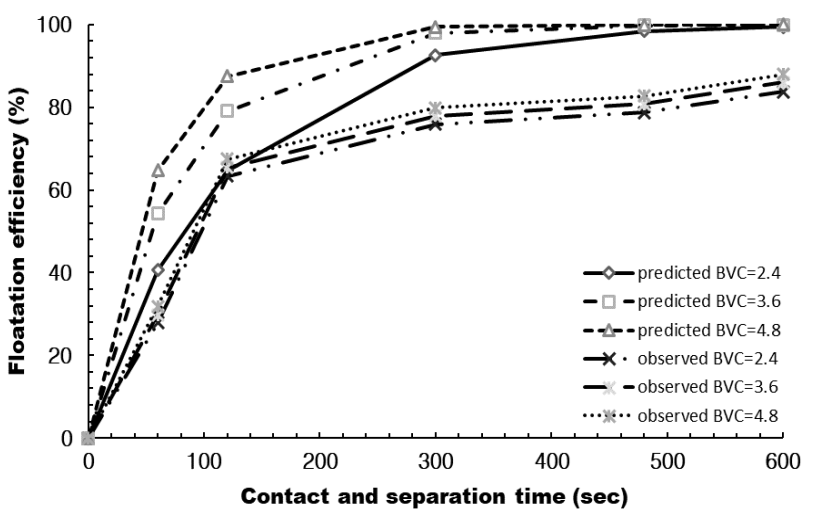

(c) MPs $125 \sim 150 \mu \mathrm{m}$

Fig. 8. Comparison of experimental values according to MPs size and simulation values of bubble volume concentration.

의 범위에서 실험에 적용하였다. ${ }^{22)}$

$\mathrm{BVC}$ 를 변화시켜가며 3.3 초기 충돌-부착 계수에서 확인한 $\alpha_{p b}$ 값에 대한 평균값을 적용하여 모의한 결과와 부상분리 실 험을 실시한 결과는 다음의 Fig. 8과 같이 나타냈다. Fig.8(a) 와 Fig.8(b)에서는 $120 \mathrm{sec}$ 이후에 부상효율이 안정화되는 결과를 보였으며, Fig.8(c)에서는 $300 \mathrm{sec}$ 이후에 안정화되는 부상효율을 보였다. 실험값과 모의값 비교한 결과 MPs 입자 크기에 상관없이 BVC 값이 커질수록 MPs 입자의 부상분리 효율은 상승하였다. 이러한 결과는 기포 체적농도가 증가하 면서 MPs와 기포의 충돌하는 효율의 증가하면서 그에 따라
제거효율이 증가하는 결과이며, $125 \sim 150 \mu \mathrm{m}$ 에서 상대적으 로 긴 분리시간을 가지는 것은 초기 부착효율에 영향으로 여 겨진다. 실험결과에 따라 MPs 입자의 낮은 초기 충돌-부착 특성을 보완하기 위해서는 보다 높은 범위의 BVC 운전을 통 하여 입자의 분리 효율을 향상시킬 수 있음을 확인할 수 있었 다.

\section{4. 결 론}

본 연구에서는 수체에서 다양한 문제를 야기하는 MPs 입자 의 부상분리를 위하여 단순하고 간편한 SCC 모델을 통하여 MPs 입자의 충돌부착 효율 및 부상분리 특성을 살펴보았다. 또한, 이론적인 $\mathrm{SCC}$ 충돌효율을 기초로 얻어진 MPs 입자의 부상분리 효율과 실질적인 실험결과의 제거효율을 비교하고 $\mathrm{SCC}$ 모델에 대한 적용성을 확인하였으며, 일련의 고찰을 통 하여 다음과 같은 결론을 도출하였다.

1) SCC 모델에 의한 MPs 입자의 충돌효율을 평가한 결과, 중력에 의한 침강과 관성력보다는 브라운 확산과 입자의 포착 이 MPs 입자의 부상분리에 주된 영향을 미치는 것으로 나타났 다. SCC 모델에 의한 전반적인 MPs 입자의 충돌효율 예측결 과는 기존의 kaolin 입자와 유사한 패턴을 보였다.

2) 충돌효율을 통한 MPs의 부상효율을 실험 관측값과 모델 예측값을 비교한 결과, MPs 입자크기에 따라 분리효율의 차 이를 보였다. 또한, 충돌과 부착이 시작되는 초기 부상시간 $(60$ $\sim 120 \mathrm{sec}$ )에서는 관측값과 예측값 간의 차이가 컸으나, 부상 분리가 점차 마무리되는 최종 부상시간 $(600 \mathrm{sec})$ 에 이르러서 는 유사한 분리효율을 나타내었다.

3) 초기 부상시간에서의 효율 차이는 MPs 입자가 일반적 무기입자와 특성이 다른 점에서 기인된 것으로 판단되어 MPs 입자의 초기 충돌-부착 계수 $\left(\alpha_{p b}\right)$ 를 평가한 결과, 작은 입자 (MPs 입경, $27 \sim 32 \mu \mathrm{m}$ )에서는 $0.03 \sim 0.1$, 중간 크기의 입자 (MPs 입경, $53 \sim 63 \mu \mathrm{m}$ )에서는 $0.01 \sim 0.1$, 그리고 큰 크기의 입자(MPs $125 \sim 150 \mu \mathrm{m}$ )에서는 $0.003 \sim 0.01$ 의 값을 보였다. 기존 무기입자인 kaolin 입자의 초기 충돌-부착 계수 0.3 0.4 의 범위에 비하여 MPs 입자는 상대적으로 낮은 값을 나 타내었다.

4) MPs 입자의 작은 초기 충돌-부착 계수값에 따라 나타나 는 입자의 낮은 부상분리 효율을 보완하기 위하여 기포체적농 도를 보다 높여서 운전하면, MPs 입자의 부상분리 효율을 향 상시킬 수 있음을 실험을 통하여 확인하였다.

이와 같이 SCC 모델을 통하여 부상분리 공정에서 MPs 입자 의 부상분리 효율을 예측하고 그 적용가능성을 확인할 수 있었 다. 다만 본 실험에 사용되지 못한 수 $\mu \mathrm{m}$ 또는 그 이하의 범위의 MPs 입자에 대한 SCC 모델 적용성은 실제의 실험 평가에 한계 가 있어서 검증하지 못하였으며, 이러한 submicron 범위의 MPs 입자에 대한 후속 연구가 필요할 것으로 여겨진다. 


\section{Acknowledgements}

본 연구는 한국연구재단의 연구비 지원(과제번호: NRF-2019 R1A2C1006441)으로 수행되었으며, 일부는 환경부의 재원으로 한국환경산업기술원 환경정책기반공공기술개발사업의 지원 (2018000200001)을 받아 연구되었습니다.

\section{References}

1. A. B. Castillo, I. Al-Maslamani, J. P. Obbard, Prevalence of microplastics in the marine waters of Qatar, Mar. Pollut. Bull., 111(1-2), 260-267(2016).

2. D. Eerkes-Medrano, R. C. Thompson, D. C. Aldridge, Microplastics in freshwater systems: a review of the emerging threats, identification of knowledge gaps and prioritisation of research needs, Water Res., 75, 63-82(2015).

3. J. Li, H. Liu, J. P. Chen, Microplastics in freshwater systems: a review on occurrence, environmental effects, and methods for microplastics detection, Water Res., 137, 362-374(2018).

4. M. Cole, P. Lindeque, C. Halsband, T. S. Galloway, Microplastics as contaminants in the marine environment: a review, Mar. Pollut. Bull., 62(12), 2588-2597(2011).

5. G. Lienezeit, E. Liebezeit, Synthetic particles as contaminants in German beers, Food Addit. Contam. Part A, 31(9), 1574-1578(2014).

6. J. Teng, Q. Wang, W. Ran, D. Wu, Y. Liu, S. Sun, H. Liu, R. Cao, J. Zhao, Microplastics in cultured oysters from different coastal areas of China, Sci. Total Environ., 653, 1282-1292(2019).

7. M. Pivokonsky, L. Cermakova, K. Novotna, P. Peer, T. Cajthaml, V. Janda, Occurrence of microplastics in raw and treated drinking water, Sci. Total Environ., 643, 1644-1651 (2018).

8. C. J. Moore, Synthetic polymers in the marine environment: a rapidly increasing, long-term threat, Environ. Res., 108(2), 131-139(2008).

9. B. Ma, W. Xue, C. Hu, H. Liu, J. Qu, L. Li, Characteristics of microplastic removal via coagulation and ultrafiltration during drinking water treatment, Chem. Eng. J., 359, 159-167 (2019).

10. K. H. Kim, J. H. Hwang, J. S. Choi, Y. W. Huh, J. W. Park, The effects of microplastics on marine ecosystem and future research directions, Korean J. Environ. Biol., 37(4), 625-639 (2019).

11. E. L. Teuten, S. J. Rowland, T. S. Galloway, R. C. Thompson, Potential for plastics to transport hydrophobic contaminants, Environ. Sci. Technol., 41(22), 7759-7764(2007).

12. D. Brennecke, B. Duarte, F. Paiva, I. CaÇador, J. Canning-Clode, Microplastics as vector for heavy metal contamination from the marine environment, Estuar. Coast. Shelf Sci., 178, 189-195(2016).

13. Y. Wang, Y. Li, L. Tian, L. Ju, Y. Liu, The removal efficiency and mechanism of microplastics enhancement by positive modification dissolved air flotation, Water Environ. Res., 1352(2020).

14. J. K. Edzwald, Dissolved air flotation and me, Water Res., 44(7), 2077-2106(2010).

15. B. Michaux, M. Rudolph, M. A. Reuter, Challenges in predicting the role of water chemistry in flotation through simulation with an emphasis on the influence of electrolytes, Miner. Eng., 125, 252-264(2018).

16. D.-H. Kwak, K.-C. Lee, Effect of floated sludge recycling on phosphorus removal in dissolved air flotation, ICE Water Management, 168(6), 270-279(2015).

17. J. P. Malley, J. K. Edzwald, Conceptual model for dissolved-air flotation in drinking water treatment, J. Water Supply Res. Technol. AQUA, 40(1), 7-17(1991).

18. J. K. Edzwald, Principles and applications of dissolved air flotation, Water Sci. Technol., 31(3-4), 1-23(1995).

19. J. W. Yang, Y. H. Choi, I. S. Chae, M. S. Kim, Y. H. Jeong, T. G. Kim, D. H. Kwak, Comparative evaluation on collision and particle separation efficiency between $\mathrm{CO}_{2}$ bubbles and air bubbles using contact zone model of flotation process, J. Korean Soc. Water Environ., 35(1), 64-71(2019).

20. D.-H. Kwak, M. S. Kim, Feasibility of carbon dioxide bubbles as a collector in flotation process for water treatment, J. Water Supply Res. T., 62(1), 52-65(2013).

21. K. Fukushi, N. Tambo, Y. Matsui, A kinetic model for dissolved air flotation in water and wastewater treatment, Water Sci. Technol., 31(3-4), 37-47(1995).

22. Y. H. Yoo, Solid separation and flotation characteristics using carbon dioxide micro-bubble, Master's Thesis, Chonbuk National University, 59-62, 80-91(2011). [Korean Literature]

23. J. K. Edzwald, Contact zone modeling and the role of pretreatment in DAF performance, In Dissolved Air Flotation, CIWEM, London, UK, pp. 9-23(1997).

24. M. Y. Han, Y. H. Park, D.-H. Kwak, K. H. Jeon, Effect of particle and bubble size on the removal efficiency in DAF, Asian Waterqual 2001 Asia-Pacific Regional Conference, 15(3), 197-202(2001)

25. J. Harrhoff, J. K. Edzwald, Dissolved air flotation modeling: insight and shortcomings, J. Water Supply Res. T., 53(3), 127-150(2004)

26. M.-Y. Han, Y.-H. Park, J. Lee, J.-S. Shim, The size characteristics of microbubbles in DAF according to pressure conditions, J. Korean Soc. Water Wastewater, 16(2), 177-182 (2002).

27. D. M. Leppinen, S. B. Dalziel, Bubble size distribution in dissolved air flotation tanks, J. Water Supply Res. T., 53(8), 531-543(2004).

28. A. L. Lagvankar, R. S. Gemmel, A size-density relationship for flocs, J. Am. Water Works Assoc., 60(9), 1040-1046(1968).

29. R.-H. Yoon, Microbubble flotation, Miner. Eng., 6(6), 619-630(1993).

30. M. Lapointe, J. M. Farner, L. M. Hernandez, N. Tufenkji, Understanding and improving microplastics removal during water treatment: impact of coagulation and flocculation, Environ. Sci. Technol., 54(14), 8719-8727(2020). 
31. M. R. Teixeira, V. Sousa, M. J. Rosa, Investigating dissolved air flotation performance with cyanobacterial cells and filaments, Water Res., 44(11), 3337-3344(2010).

32. D. H. Kwak, H. J. Jung, S. B. Kwon, E. J. Lee, C. H. Won, J. W. Lee, S. J. Yoo, Rise velocity verification of bubble-floc agglomerates using population balance in DAF process, J. Water Supply Res. T., 58(2) 85-94(2009).

33. J. A. Kitchener, R. J. Gochin, The mechanism of dissolved air flotation for potable water: basic analysis and a proposal, Water Res., 15(5), 585-590(1981).

34. D. H. Kawk, H. J. Jung, S. J. Kim, C. H. Won, J. W. Lee, Separation characteristics of inorganic particles from rainfalls in dissolved air flotation: a Korean perspective, Sep. Sci. Techol., 40(14), 3001-3015(2005).

35. R. Greenwood, B. Lapcikova, M. Surynek, K. Waters, L. Lapcik Jr., The zeta potential of kaolin suspensions measured by electrophoresis and electroacoustics, Chem. Pap., 61(2), 83-92(2007).

36. D. Y. Choi, S. J. Kim, H. J. Jung, S. I. Lee, D. H. Paik, J. W. Lee, D.-H. Kwak, Effect of zeta potential of clay and algae particles on flotation efficiency, J. KSWW, 19(4), 437-445(2005).

37. F. S. Lameiras, A. L. D. Souza, V. A. R. Melo, E. H. M. Nunes, I. D. Braga, Measurement of the zeta potential of planar surfaces with a rotating disk, Mater. Res., 11(2), 217-219(2008).

38. G. Dermont, M. Bergeron, M. Richer-Laflche, Soil washing for metal removal: a review of physical/chemical technologies and field applications, J. Hazard. Mater., 152(1), 1-31(2008).

\section{Declaration of Competing Interest}

The authors declare that they have no known competing financial interests or personal relationships that could have appeared to influence the work reported in this paper.

\section{Authors and Contribution Statement}

\section{Min-Ho Jang}

Department of Bio-convergence Science, Jeonbuk National University, Master Course Student, ORCID (1) 0000-0002-3528-1506: Data curation, Visualization, Writing - original draft.

\section{Yong-Ho Choi}

Department of Bio-convergence Science, Jeonbuk National University, Ph.D. Student, ORCID(1) 0000-0001-5754-2538: Data curation, Visualization, Data analysis.

\section{Heung-Joe Jung}

Department of Biological Science, Sinkyung University, Professor, ORCID(1) 0000-0001-5508-9346: Conceptualization, Data analysis, Methodology, Supervision, Writing - review and editing.

\section{Yong-Hoon Jeong}

Center for Jeongeup Academy-Industry Cooperation, Jeonbuk National University, Research Professor, ORCiD [0] 0000-0002-7501 -8729: Conceptualization, Data analysis, Validation.

\section{Dong-Heui Kwak}

Department of Bio-convergence Science, Jeonbuk National University, Professor, ORCID (10 0000-0001-5692-7372: Conceptualization, Funding acquisition, Project administration, Resources, Writing review and editing. 